\title{
PETROLEUM ETHER EXTRACT OF CISSUS QUADRANGULARIS (LINN.) ENHANCES BONE MARROW MESENCHYMAL STEM CELL PROLIFERATION AND FACILITATES OSTEOBLASTOGENESIS
}

\author{
Bhagath Kumar Potu, ${ }^{\text {I }}$ Kumar MR Bhat, ${ }^{\text {I Muddanna S Rao, }}$ Gopalan Kutty \\ Nampurath, ${ }^{\mathrm{II}}$ Mallikarjuna Rao Chamallamudi, ${ }^{\mathrm{II}}$ Soubhagya Ranjan Nayak, ${ }^{\mathrm{III}}$ \\ Manjunatha S Muttigi ${ }^{\mathrm{IV}}$
}

doi: $10.1590 / \mathrm{S1807-59322009001000010}$

Potu BK, Bhat KMR, Rao MS, Nampurath GK, Chamallamudi MR, Nayak SR, Muttigi MS. Petroleum ether extract of cissus quadrangularis (linn.) enhances bone marrow mesenchymal stem cell proliferation and facilitates osteoblastogenesis. Clinics. 2009;64(10):993-8.

OBJECTIVE: To evaluate the effects of the petroleum ether extract of Cissus quadrangularis on the proliferation rate of bone marrow mesenchymal stem cells, the differentiation of marrow mesenchymal stem cells into osteoblasts (osteoblastogenesis) and extracellular matrix calcification. This study also aimed to determine the additive effect of osteogenic media and Cissus quadrangularis on proliferation, differentiation and calcification.

METHODS: MSCs were cultured in media with or without Cissus quadrangularis for 4 weeks and were then stained for alkaline phosphatase. Extracellular matrix calcification was confirmed by Von Kossa staining. marrow mesenchymal stem cells cultures in control media and osteogenic media supplemented with Cissus quadrangularis extract (100, 200, $300 \mu \mathrm{g} / \mathrm{mL})$ were also subjected to a cell proliferation assay (MTT).

RESULTS: Treatment with 100, 200 or $300 \mu \mathrm{g} / \mathrm{mL}$ petroleum ether extract of Cissus quadrangularis enhanced the differentiation of marrow mesenchymal stem cells into ALP-positive osteoblasts and increased extracellular matrix calcification. Treatment with $300 \mu \mathrm{g} / \mathrm{mL}$ petroleum ether extract of Cissus quadrangularis also enhanced the proliferation rate of the marrow mesenchymal stem cells. Cells grown in osteogenic media containing Cissus quadrangularis exhibited higher proliferation, differentiation and calcification rates than did control cells.

CONCLUSION: The results suggest that Cissus quadrangularis stimulates osteoblastogenesis and can be used as preventive/ alternative natural medicine for bone diseases such as osteoporosis.

KEYWORDS: Cissus quadrangularis; Mesenchymal stem cells; Osteoblastogenesis; Osteoporosis; Osteoblast.

\section{INTRODUCTION}

The repair of bone defects secondary to trauma,

\footnotetext{
'Department of Anatomy, Kasturba Medical College, Manipal University Manipal, Karnataka, India.

"Department of Pharmacology, Manipal College of Pharmaceutical Sciences - Manipal, Karnataka, India.

IIIDepartment of Anatomy, Kasturba Medical College, Manipal University - Mangalore, Karnataka, India.

${ }^{\text {IV } D e p a r t m e n t ~ o f ~ B i o c h e m i s t r y, ~ K a s t u r b a ~ M e d i c a l ~ C o l l e g e, ~ M a n i p a l ~ U n i v e r-~}$ sity - Manipal, Karnataka, India.

Email:kummigames@yahoo.com

Tel.: 0820.2922327

Received for publication on January 27, 2009

Accepted for publication on July 08, 2009
}

osteoporosis, osteomyelitis and nonunion fracture poses a significant problem for many clinicians, particularly orthopedic, head and neck, and plastic surgeons. Several strategies have been employed to promote the bone-healing process. Bone marrow mesenchymal stem cells (MSCs) have recently received widespread attention due to their potential use in tissue engineering applications. MSCs are defined as self-renewable, multipotent progenitor cells with the capacity to differentiate into several distinct mesenchymal lineages and are thus excellent candidates for tissue engineering.

As a part of our continuing search for biologically active natural anti-osteoporotic agents, we have extensively 
evaluated the efficacy of petroleum ether extract of Cissus quadrangularis Linn. (CQ) on osteomodulation in a rat model. CQ (Veldt Grape or Winged Treebine), a vine that belongs to the family Vitaceae, is one of the most frequently used medicinal plants in India. ${ }^{1}$ This is an edible plant found in the warmer regions of India, Sri Lanka, Malaysia, Java and West Africa. ${ }^{2}$ The plant, commonly known as "bone setter", is referred to as Asthisandhani in Sanskrit and Hodjod in Hindi because of its ability to join bones. ${ }^{3}$ The plant and its medicinal properties have been described in ancient books such as Bhawa prakash. ${ }^{4}$ The fresh stem and leaves of $\mathrm{CQ}$ are used for the treatment of hemorrhoids, menstrual disorders, scurvy and flatulence. Extracts of this plant are reported to contain phytoestrogenic steroids, ascorbic acid, carotene, calcium and anabolic steroids. ${ }^{5-10}$ The plant extract has been shown to have bone fracturehealing properties in several in vivo studies. ${ }^{11-16}$ Murthy and colleagues reported the antibacterial and antioxidant activities of the CQ extract. ${ }^{17}$ Various formulations now contain extracts of CQ in combination with other compounds and are used to manage overweight conditions and obesity ${ }^{18}$ as well as to treat complications resulting from these conditions, notably metabolic syndrome (syndrome $\mathrm{X}$ ). $\mathrm{CQ}$ was also recently shown to have significant effects in periodontal regenerative therapy. ${ }^{19}$ Using an ovariectomized rat model for osteoporosis, Shirwaikar et al. found that the ethanolic extract of CQ has bone-healing properties..$^{15}$ Recently, we have shown that the petroleum ether extract of $\mathrm{CQ}$ enhances fetal bone growth and ossification. ${ }^{20}$

Phytochemical analyses of CQ have revealed high contents of ascorbic acid, carotene, anabolic steroidal substances and calcium. ${ }^{7}$ The stem contains two asymmetric tetracyclic triterpenoids and two steroidal principles. The presence of $\beta$-sitosterol, $\delta$-amyrin, $\delta$-amyrone and flavanoids (quercetin) has also been reported. ${ }^{21,22}$ All of these components have potentially different metabolic and physiologic effects.

Although different uses of CQ have been investigated, the exact mechanism of its bone-healing properties has not been evaluated. Therefore, in the present study, we aimed to evaluate the effects of petroleum ether extract of CQ on bone marrow mesenchymal stem cell proliferation and osteogenic differentiation.

\section{MATERIALS AND METHODS}

Plant extract: The stems of Cissus quadrangularis (CQ) were collected from the Nalgonda District of Andhra Pradesh, India, and were identified and authenticated by a botanist. A voucher specimen was deposited in the pharmacology department of Manipal University, Manipal.
The fleshy stems $(2.5 \mathrm{~kg})$ were washed, cut into small pieces, air-dried and crushed into powder. Stem powder was exhaustively extracted with $95 \%$ ethanol using a Soxhlet apparatus, and a yield of $225 \mathrm{~g}$ was obtained. The total ethanol extract was concentrated in a vacuum, after which the extract was dissolved in water and the solution was partitioned with petroleum ether. A total of $18.2 \mathrm{~g}$ of petroleum ether extract was obtained.

Animals: Three-month-old male Wistar rats weighing approximately $225 \mathrm{~g}(\mathrm{n}=30)$ were housed in the central animal research facility of Manipal University. The rats were housed in sanitized polypropylene cages containing sterile paddy husks as bedding. The animals were maintained under controlled temperature $\left(23 \pm 2^{\circ} \mathrm{C}\right)$ and humidity $(50 \pm$ $5 \%$ ) conditions and a 12-hour light-dark cycle. All animals were allowed free access to distilled water and commercial diet. The studies were approved by the Institutional Animal Ethical Committee of Kasturba Medical College, Manipal, according to guidelines prescribed by the Committee for the Purpose of Control and Supervision of Experiments on Animals (CPCSEA), Government of India.

Isolation of bone marrow cells: Three male Wistar rats of the albino strain were anesthetized with ether. The tibia and femur bones were collected under sterile conditions and placed in Dulbecco's Modified Eagle's Medium (DMEM) supplemented with $0.2 \%$ antibiotics. The bones were cut at both ends, and the bone marrow was flushed with $5 \mathrm{~mL}$ of media. Bone marrow cells were collected separately from three different animal bones. The cells were mixed gently and filtered through a membrane filter to remove debris. The filtrate was centrifuged at 3,000 rpm for $5 \mathrm{~min}$, and the cells were washed with DMEM and used to seed cultures. After three days, the floating cells were discarded; the media were changed every third day thereafter. These three cell lines were independently subjected to all of the assays in this project.

Primary cell culture and differentiation: The isolated bone marrow mesenchymal stem cells were cultured in 6 -well Corning polystyrene cell culture plates $(50,000$ cells/well for staining purposes and 10,000 cells/well for the MTT assay), in two different culture media: basal medium (DMEM with $15 \%$ fetal bovine serum, $100 \mathrm{U} / \mathrm{mL}$ penicillin and $100 \mu \mathrm{g} / \mathrm{mL}$ streptomycin) and osteogenic medium (DMEM with 10\% fetal bovine serum (Gibco), 1 $\mu \mathrm{M}$ dexamethasone (Sigma), $10 \mathrm{mM}$ glycerol phosphate (Sigma), $0.05 \mathrm{mM}$ ascorbic acid (Sigma), $100 \mathrm{U} / \mathrm{mL}$ penicillin and $100 \mu \mathrm{g} / \mathrm{mL}$ streptomycin (Gibco)). The cells were incubated at $37^{\circ} \mathrm{C}$ in a $5 \% \mathrm{CO}_{2}$ atmosphere for one week with regular changes of media. Once monolayer cells were confluent, they were trypsinized and subcultured as required. Cells grown in either basal or osteogenic media 
were treated with different doses of CQ extract $(100,200$ and $300 \mu \mathrm{g} / \mathrm{mL}$ ) for up to 28 days. The treated/untreated cells were then subjected to alkaline phosphatase (ALP), Von Kossa staining and MTT assays.

Histochemical localization of alkaline phosphatase (ALP): About 50,000 MSCs were plated in 6-well dishes. The MSCs were washed twice with PBS and fixed with $4 \%$ paraformaldehyde at $4^{\circ} \mathrm{C}$ for $30 \mathrm{~min}$. After fixation, cells were washed three times with distilled water and then airdried for $10 \mathrm{~min}$. The cells were then stained with ALP for 30 min with fresh naphthol AS-MX phosphatase solution $(0.2 \mathrm{~g} / \mathrm{L})$ (Sigma) containing fast red violet B salt $(0.42$ $\mathrm{g} / \mathrm{L}$ ) (Sigma) in $100 \mathrm{mM}$ Tris-HCl (pH 0.9) (Sigma) at room temperature. ALP-positive cells were stained pink.

Von Kossa staining: Cells were rinsed with phosphatebuffered saline (PBS) and fixed in 4\% paraformaldehyde for $30 \mathrm{~min}$. The cells were incubated in 5\% silver nitrate in the dark and then exposed to ultraviolet light for $1 \mathrm{hr}$. Cells were then washed with distilled water, treated with $2.5 \%$ sodium thiosulfate for $5 \mathrm{~min}$, washed again with distilled water and counterstained with methyl green. The calcified extracellular matrix appeared as black nodules.

Cell proliferation assay: The MSCs were seeded in four 96 -well plates at a density of $1 \times 10^{4}$ cells/well. These cells were grown either in control/basal media (CM) or in osteogenic media $(\mathrm{OM})$. Both groups of cells were treated with $300 \mu \mathrm{g} / \mathrm{mL}$ petroleum ether extract of CQ for 48 hours. After the incubation, $20 \mu \mathrm{L}$ of MTT stock solution was added to each well and incubated for $4 \mathrm{hr}$ at $37^{\circ} \mathrm{C}$. Then, the formazan crystals were dissolved in DMSO for $1 \mathrm{hr}$ at room temperature. The absorbance of the colored solution was measured using an ELISA plate reader at a wavelength of $570 \mathrm{~nm}$. Data were analyzed using the Student's $\mathrm{t}$-test in GraphPad. The represented data are the average value of three different assays. The growth rate of the control (Figure 1A, $\mathrm{CM}=$ bone marrow mesenchymal stem cells grown in basal media) cells was determined and set as $100 \%$. The growth
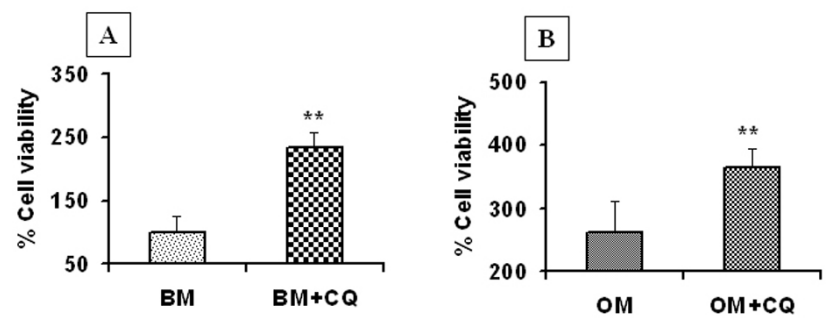

Figure 1 - Cissus Quadrangularis (CQ) treatment increases the proliferation rate of undifferentiated MSCs: Proliferation assay (MTT assay) of MSCs grown in basal media (A) and osteogenic media (B). Treatment with $300 \mu \mathrm{g} /$ $\mathrm{mL} C Q$ extract increases the proliferation rate by two-fold in basal media $(\mathrm{CM}+\mathrm{CQ})$ and by three-fold in osteogenic media $(\mathrm{OM}+\mathrm{CQ}) . * *=\mathrm{P}<0.01$, as compared to control cells. Data is represented as a percentage and is an average of three independent experiments rates of cells grown in basal media and treated with $\mathrm{CQ}(\mathrm{CM}+$ $\mathrm{CQ})$, cells grown in osteogenic media $(\mathrm{OM})$ and cells grown in osteogenic media and treated with plant extract $(\mathrm{OM}+\mathrm{CQ})$ were compared to that of the control group (CM).

\section{RESULTS}

CQ extract increases the proliferation rate of undifferentiated MSCs: The addition of $300 \mu \mathrm{g} / \mathrm{mL}$ petroleum ether extract of CQ to undifferentiated MSCs increased their proliferation rate significantly (by 2-fold) in comparison with that of cells grown in basal media alone (Figure $1 \mathrm{~A}, \mathrm{P}<0.01$ ). The proliferation rate of MSCs cultured in basal media with CQ extract was the same as that of MSCs grown in osteogenic media alone (compare Figures 1A and 1B). Furthermore, treatment of the MSCs grown in osteogenic media with plant extract resulted in a 3-fold increase in the cell proliferation rate in comparison with cells grown in basal media alone (Figure 1B). Thus, our results from three independent assays show that treatment of undifferentiated MSCs with the plant extract alone has a significant influence on proliferation, while an additive effect was seen when cells were also treated with osteogenic media.

CQ extract induces differentiation of MSCs into osteoblasts: MSCs grown in basal media (DMEM) did not differentiate into osteoblasts and did not show ALP activity even after 28 days (Figure 2A). Interestingly, MSCs grown in basal media and supplemented with CQ
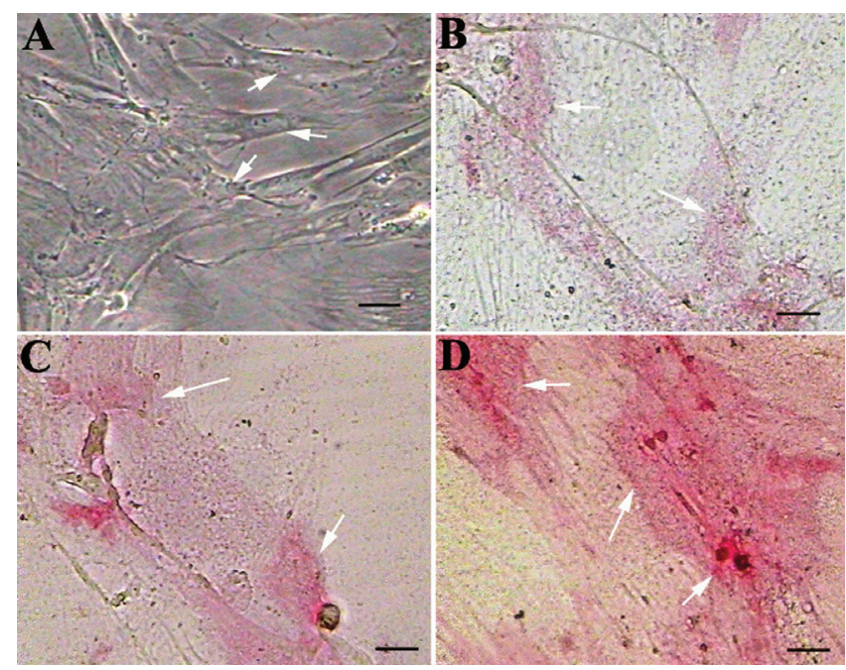

Figure 2 - CQ enhances differentiation of bone marrow mesenchymal stem cells (MSCs) into osteoblasts: MSCs were grown in basal media and supplemented with 100,200 or $300 \mu \mathrm{g} / \mathrm{mL}$ CQ plant extract (B, C and D, respectively) and stained for alkaline phosphatase (ALP). Note that MSCs grown in the control media are negative for ALP (A), cells grown in the basal media supplemented with 100, $200 \mu \mathrm{g} / \mathrm{mL} \mathrm{CQ} \mathrm{(B,C)} \mathrm{are} \mathrm{weakly} \mathrm{posi-}$ tive for ALP, and cells supplemented with $300 \mu \mathrm{g} / \mathrm{mL}$ CQ (D) are strongly positive for ALP, suggesting differentiation into osteoblasts. Arrows indicate undifferentiated MSCs in A and differentiating MSCs in B, C and D. Scale bar $=25 \mu \mathrm{m}$. Magnification $=20 \times$ 
extract differentiated into osteoblasts, as identified by ALP activity (Figures 2B, C, D). Mesenchymal cells cultured in basal media containing $100 \mu \mathrm{g} / \mathrm{mL}$ CQ extract were weakly positive for ALP activity (Figure 2B), while cells cultured in media containing $200 \mu \mathrm{g} / \mathrm{mL}$ or $300 \mu \mathrm{g} / \mathrm{mL}$ CQ extract showed a dose-dependent increase in ALP activity (Figures $2 \mathrm{C}$ and 2D). Furthermore, MSCs grown in basal media with different concentrations of CQ extract began to show ALP activity by the $15^{\text {th }}$ day of treatment; most cells were strongly positive for ALP by the end of the $20^{\text {th }}$ day of treatment. It has been shown that untreated MSCs must be cultured in osteogenic media for 28 days before ALP-positive, differentiated osteoblasts can be identified. ${ }^{23}$

However, our results show a dose-dependent increase in ALP activity in cells grown in osteogenic media with 100, 200 and $300 \mu \mathrm{g} / \mathrm{mL}$ of CQ extract (Figures 3B, 3C and 3D, respectively), as compared to the MSCs grown in osteogenic media alone (Figure $3 \mathrm{~A}$ ), beginning at the $7^{\text {th }}$ day of the treatment. By the $15^{\text {th }}$ day of CQ treatment in osteogenic media, more than $95 \%$ of the cells were positive for ALP. Thus, CQ extract alone can differentiate MSCs into ALPpositive osteoblast cells, and CQ can also accelerate the osteoblast differentiation process of MSCs in osteogenic media in an additive fashion. The figures are representative photographs of three independent experiments that showed similar results.

Effect of CQ extract on the mineralization of extracellular matrix: MSCs grown in basal media alone did not show any signs of mineralization in the extracellular matrix (Figure 4A) even after 28 days. However, MSCs grown in the basal media and treated with CQ extract $(300 \mu \mathrm{g} / \mathrm{mL})$ showed calcium
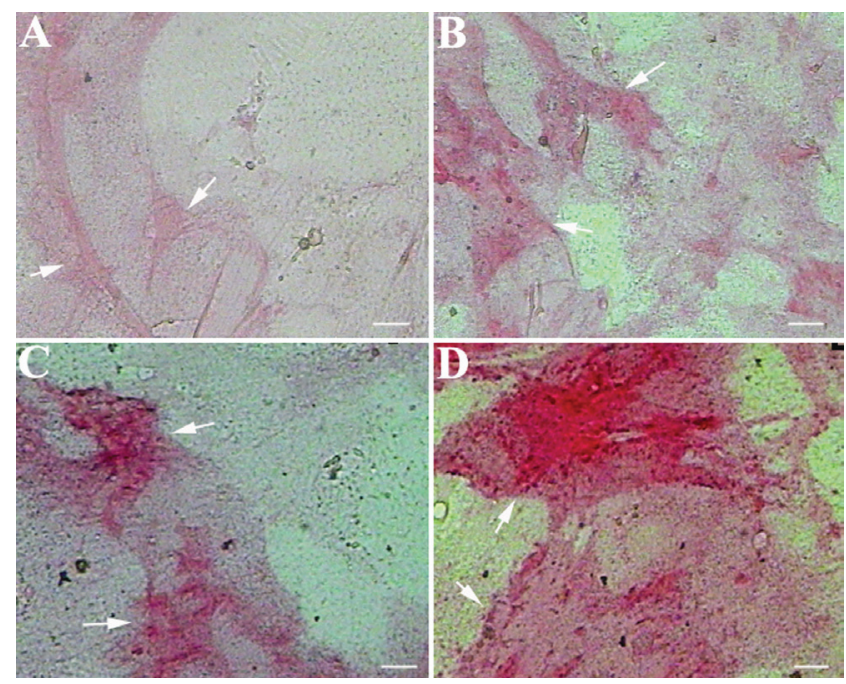

Figure 3 - Treatment of undifferentiated MSCs with CQ extract in osteogenic media accelerates osteoblast differentiation: MSCs grown in osteogenic media alone show mild ALP activity by the 7th day of the treatment (A). Furthermore, MSCs grown in osteogenic media supplemented with 100, 200 or $300 \mu \mathrm{g} / \mathrm{mL}$ CQ extract show intense, dose-dependent ALP activity (B, C and D, respectively). Arrows indicate differentiating MSCs. Scale bar $=25 \mu \mathrm{m}$
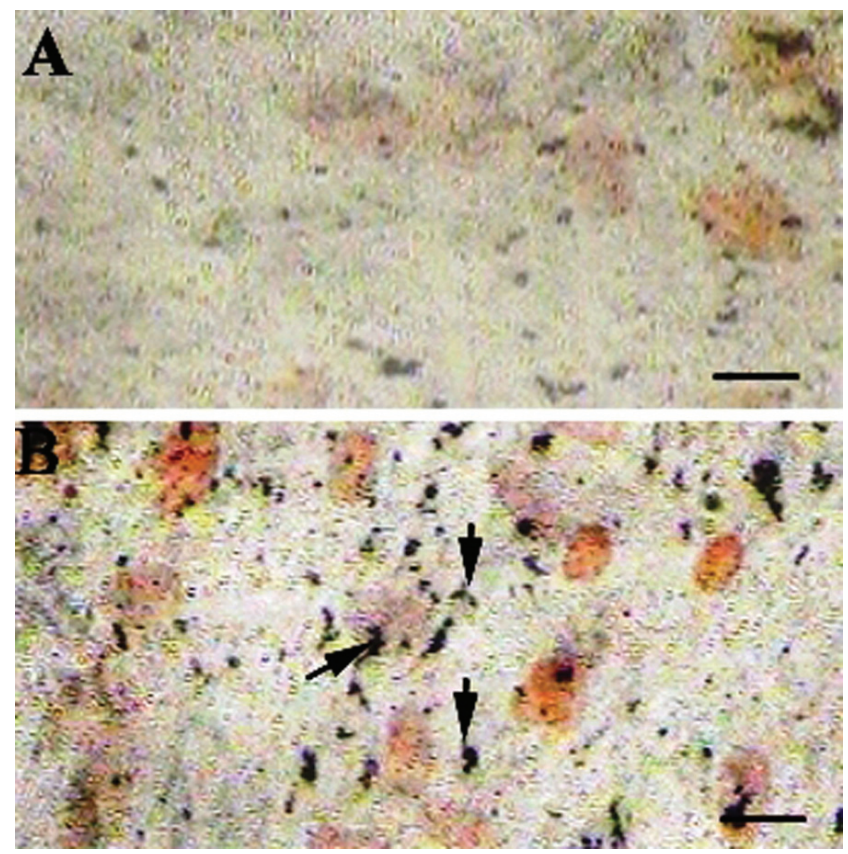

Figure 4 - CQ treatment induces extracellular matrix mineralization: Undifferentiated MSCs grown in basal media did not display deposition of calcium salt in the extracellular matrix (A) even after 28 days of culture. Treating undifferentiated MSCs with $300 \mu \mathrm{g} / \mathrm{mL}$ CQ extract promoted mild deposition of calcium after 15 days of treatment. Scale bar $=50 \mu \mathrm{m}$

deposition in the extracellular matrix (Figure 4B) as early as 15 days after the beginning of the treatment. The MSCs cultured in the osteogenic media alone showed mineralization after 28 days (Figure 5A). Furthermore, cells treated with osteogenic media supplemented with CQ extract (300 $\mu \mathrm{g} /$ $\mathrm{mL}$ ) showed a greater extent of mineralization (Figure 5B), which was evident as early as the $7^{\text {th }}$ day. Thus, our result suggests that CQ extract not only induces the differentiation of MSCs into osteoblasts but also causes the differentiated osteoblasts to deposit calcium salts in the extracellular matrix.

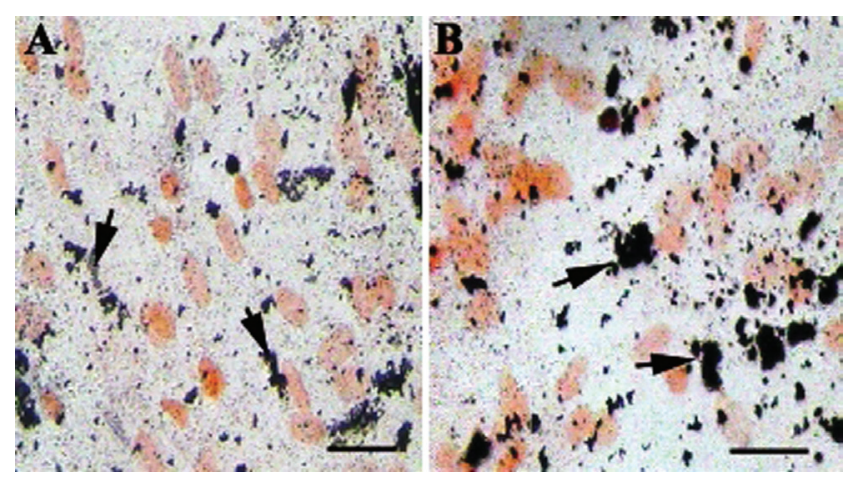

Figure 5 - CQ treatment enhances extracellular matrix mineralization by differentiating MSCs grown in osteogenic media: MSCs grown in osteogenic media show mineralization of the extracellular matrix after 28 days (A). Interestingly, more intense mineralization was observed by the $7^{\text {th }}$ day when MSCs grown in osteogenic media were treated with $300 \mu \mathrm{g} / \mathrm{mL} \mathrm{CQ}$ extract (B), suggesting strong induction of matrix calcification by the CQ extract. Scale bar $=50 \mu \mathrm{m}$ 
Additionally, undifferentiated MSCs can be differentiated into functional osteoblasts by treatment with CQ extract alone, without any other stimulator in the culture media. The figures are representative photographs of three similar independent experiments.

\section{DISCUSSION}

Human bone is composed of a mineralized organic matrix and bone cells. Osteoblasts are active mature bone cells that synthesize the organic matrix and regulate the mineralization process. Osteogenesis begins with osteoblast formation and secretion of type I collagen, which makes up about $90 \%$ of the organic bone matrix, or the osteoid. ${ }^{24}$ Once osteoblasts are active, they begin to produce large amounts of alkaline phosphatase, a phosphate-splitting enzyme that is released into the osteoid to initiate the deposition of minerals. Calcium hydroxyapatite, which comprises $70 \%$ of the bone mass, crystallizes along the cavities in the threedimensional collagen network. After mineralization, the complete bone becomes hard and rigid with the mechanical properties necessary to withstand external forces, support the body and protect the internal organs. The proliferation rate and biological activity of the osteoblasts controls the rate of bone formation, and accelerated osteoblast growth is the key factor for efficient bone repair. The reduction in bone mass in osteoporosis is due to an imbalance between bone resorption and bone formation in which the rate of resorption exceeds that of formation. The most important risk factor for osteoporosis is advanced age, in both men and women. In women, estrogen deficiency following menopause is correlated with a rapid reduction in BMD (bone mineral density). In men, a decrease in testosterone levels has similar but less pronounced effects. Other causes of osteoporosis include tobacco-smoking, low body mass index, malnutrition, alcoholism, insufficient physical activity and exposure to heavy metals like cadmium.

Bone marrow mesenchymal stem cells are the source of bone-forming osteoblasts. ${ }^{24}$ The results of our experiments show that the petroleum ether extract of CQ can stimulate the differentiation of mesenchymal stem cells into osteoblasts in a dose-dependent manner even in the absence of osteogenic conditioning media. This activity of the plant extract is increased further in the presence of osteogenic media. The plant extract also facilitated extracellular matrix mineralization, which was more pronounced in the presence of osteogenic media. Finally, the presence of plant extract in the control and osteogenic media stimulated the proliferation rate of MSCs.

Our results clearly show that the CQ plant extract enhances the proliferation and differentiation ability of MSCs into osteoblasts. ALP activity, the most widely recognized biomarker for osteoblast activity ${ }^{25}$ was enhanced by a short treatment with CQ. Our findings are in line with several previous in vivo experiments that have demonstrated that CQ promotes ALP activity and enhances collagen synthesis in the fracture-healing process. ${ }^{9,15,16}$ Our results suggest that the petroleum ether fraction may contain active constituents that stimulate osteoblast differentiation and its bioactivity. The phytogenic steroids found in $\mathrm{CQ}^{7}$ may be involved in stimulating osteoblastogenesis and may act on estrogen receptors of bone cells. ${ }^{4,9,11}$

The exact molecular mechanism involved in CQpromoted osteogenesis remains to be explored. However, some evidence suggests that Wnt signaling may be involved. This pathway has been shown to play a significant role in the control of osteoblastogenesis and bone formation. Mutations in these signaling molecules are strongly associated with changes in bone mineral density and fractures. Loss-offunction mutations in LRP5 (low-density lipoprotein receptor-related protein) receptors cause osteoporosispseudoglioma syndrome, while gain-of-function mutations in the same group lead to high bone mass phenotypes. Using knockout and transgenic mouse models for Wnt pathway components, it has been established that this signaling pathway regulates many aspects of osteoblast physiology including commitment, differentiation, bone matrix formation/mineralization and apoptosis as well as its coupling with osteoclastogenesis and bone resorption. ${ }^{26}$ Therefore, it is reasonable to suggest that the active constituents of CQ may stimulate the proliferation and differentiation of MSCs and promote new bone formation through the Wnt-LRP5-ß-catenin signaling pathway for pre-osteoblast formation. Furthermore, the role of CQ in RANK-RANKL expression and osteoclast differentiation and activity needs to be identified. Recently, it has been shown that the CQ-mediated increase in osteoblast activity may be mediated through a MAPK-dependent pathway. ${ }^{27}$

Our in vitro and in vivo data suggest that CQ can be effectively used to treat various bone disorders and can also be used as a preventive measure for disorders that lead to decreased bone mineral density.

\section{ACKNOWLEDGEMENTS}

We sincerely thank Dr. Satyamoorthy, Director of Manipal Life Science Centre, Manipal, and Dr. Narga Nair, Head of Anatomy Department, KMC, Manipal, for their help and support. We thank Ms. Rekha Nayak for her technical help during this project. 


\section{REFERENCES}

1. Pongboonrod S. 1995. Mai Thed Mung Muang Thai, Bangkok. Kaeseam- Bunnakit Printing. Thailand;1995:428-9.

2. Udupa KN, Chaturvedi GN, Tripathi SN. Advances in research in Indian medicine Banaras Hindu University, Varanasi. 1970;12:165-96.

3. Sivaranjan II, Balachandran I. Ayurvedic drugs and their plant sources. Oxford and India book house publishing Co. Pvt Ltd, 1994:496.

4. Udupa KN, Prasad GC. Biomechanical and Calcium ${ }^{45}$ studies on the effect of Cissus quadrangularis in fracture repair. Ind J Med Res. 1964;52:480-7.

5. Madan Nayar. Pharmalogical study of the stem of Cissus Quadrangularis Linn. J Sci Ind Res. 1959;18:253.

6. Udupa KN, Prasad GC. Biochemical and $\mathrm{Ca}^{45}$ studies on the effect of Cissus quadrangularis in fracture healing. Ind J Med Res. 1964b;52:4807.

7. Sen SP. Preliminary clinical studies of Cissus quadrangularis. J Med Res. 1963;4:26.

8. Das PK, Sanyal AK. Studies on Cissus quadrangularis Linn. i. acetylcholine like action of the total extract. Ind J Med Res. 1964;52:637.

9. Udupa KN, Arnikar HJ, Singh LM. Experimental studies of the use of 'Cissus quadrangularis' in healing of fractures. II. Ind J Med Sci. 1961;15:551-7.

10. Singh LM, Udupa KN. Studies on "Cissus Quadrangularis" in fracture by using phosphorus 32. III. Ind J Med Sci. 1962;16:926-31.

11. Chopra SS, Patel MR, Gupta LP, Datta IC. Studies on Cissus quadrangularis in experimental fracture repair: Effect of chemical parameters in blood. Ind J Med Res. 1975;63:824-8.

12. Guha A, Prasad GC, Udupa KN. Studies on fracture healing in vivo by using radioactive strontium. Ind J Med Res. 1963;51:298-303.

13. Prasad GC, Udupa KN. Effect of Cissus quadrangularis on the healing of cortisone treated fractures. Indian J Med Res.1963;51:667-76.

14. Sanyal A, Ahmad A, Sastry M. Calcite growth in Cissus quadrangularis plant extract, a traditional Indian bone healing aid. Current science. 2005;89:1742-5.

15. Shirwaiker A, Khan S, Malini S. Antiosteoporotic activity of Ethanol extract of Cissus quadrangularis Linn on ovariectomized rat. Journal of Ethnopharmocology. 2003;89:245-50.
16. Udupa KN, Prasad GC. Further studies on the effect of Cissus quadrangularis in accelerating fracture healing. Ind $\mathrm{J}$ Med Res. 1964;52:26:35.

17. Murthy KNC, Vanitha A, Swamy M, Ravishankar GA. Antioxidant and antimicrobial activity of Cissus quadrangularis. J Med Food. 2003;6:99105 .

18. Oben JE, Ngondi JL, Momo CN, Agbor GA, Sobgui CS. The use of a Cissus quadrangularis/Irvingia gabonensis combination in the management of weight loss: a double-blind placebo-controlled study. Lipids Health Dis. 2008;31;7:12.

19. Jain A, Dixit J, Prakash D. Modulatory effects of Cissus quadrangularis on periodontal regeneration by bovine-derived hydroxyapatite in intrabony defects: exploratory clinical trial. J Int Acad Periodontol. 2008;10:59-65.

20. Potu BK, Rao MS, Kutty GN, Bhat MRK, Chamallamudi MR, Nayak SR. Petroleum ether extract of Cissus quadrangularis (Linn) stimulates the growth of fetal bone during intrauterine developmental period: a morphometric analysis. Clinics. 2008;63:815-20.

21. Mehta M, Kaur N, Bhutani K: Determination of marker constituents from Cissus quadrangularis Linn and their quantitation by HPTLC and HPLC. Phytochem Anal. 2001;12:91-105.

22. Jakikasem S, Limsiriwong P, Kajsongkarm T, Sontorntanasart T. Phytochemical study of Cissus quadrangularis. Thai J Pharm Sci. 2000;24:5.

23. Majeska RJ. Culture of Osteoblastic Cells, In Principles of Bone Biology, Bilezikian et al editors, Academic Press, San Diego, 1996.

24. Stavros CM. Birth and Death of Bone Cells: Basic regulatory mechanisms and implications for the pathogenesis and treatment of osteoporosis . Endocrine Reviews. 2000;21:115-37.

25. Cool SM, Nurcombe V. Substrate induction of osteogenesis from marrow-derived mesenchymals precursors. Stem Cells Dev. 2005;14:632-40.

26. Yavropoulou MP, Yovos JG. The role of the Wnt signaling pathway in osteoblast commitment and differentiation. Hormones. 2007;6:279-94.

27. Parisuthiman D, Singhatanadgit W, Dechatiwongse T, Koontongkaew S. Cissus quadrangularis extract enhances biomineralization through up-regulation of MAPK-dependent alkaline phosphatase activity in osteoblasts. In Vitro Cell Dev Biol Anim. 2009;45:194-200. 